Starchenko V, Metelitsa A. Study of the formation level of professional knowledge and the state of the need-motivation-value sphere of the professional culture of coaches-teachers. Theory and Methods of Physical education and sports. 2020; 1: 26-33

DOI: $10.32652 /$ tmfvs.2020.1.26-33
Старченко В, Метелица А. Исследование уровня ссоормированности профрессиональных знаний и состояния потребностно-мотивационно-ценностной сферы профессиональной культуры тренеров-преподавателей. Теорія і методика фрізичного виховання і спорту. 2020; 1: 26-33 DOI: $10.32652 / \mathrm{tmfvs} .2020 .1 .26-33$

\title{
ИССЛЕДОВАНИЕ УРОВНЯ СФОРМИРОВАННОСТИ ПРОФЕССИОНАЛЬНЫХ ЗНАНИЙ И СОСТОЯНИЯ ПОТРЕБНОСТНО-МОТИВАЦИОННО-ЦЕННОСТНОЙ СФЕРЫ ПРОФЕССИОНАЛЬНОЙ КУЛЬТУРЫ ТРЕНЕРОВ-ПРЕПОДАВАТЕЛЕЙ
}

\section{Владимир Старченко, Александр Метелица}

Гомельский государственный университет имени Франциска Скорины, Гомель, Республика Беларусь

\begin{abstract}
Анотація. У статті представлено результати дослідження рівня сформованості професійних знань та стану потребо-мотиваційно-ціннісної сфери професійної культури тренерів-викладачів. Мета. Дослідити рівень сфрормованості професійних знань та стан потребово-мотиваційно-ціннісної сфрери професійної культури тренерів-викладачів. Дослідженням були охоплені тренери-викладачі, загальна кількість яких становила 81 особу (53 чоловіки та 28 жінок). Методи. Анкетування, методи математичної статистики. Результати. Встановлено, що рівень сформованості професійних знань тренерів-викладачів «задовільний», а рівень сформованості їх потребово-мотиваційно-ціннісної сфрери професійної культури «хороший». Також встановлено, що між рівнем сформованості професійних знань та станом потребово-мотиваційно-ціннісної сфери професійної культури тренерів кореляційний зв'язок відсутній. У гендерному відношенні статистично значущої різниці між рівнями сфрормованості професійних знань тренерів чоловіків і жінок, а також між рівнями сформованості їх потребово-мотиваційно-ціннісної сфери професійної культури не виявлено. Отримані результати свідчать про невисокий рівень сформованості професійних знань тренерів-викладачів. Незважаючи на це, в профресійних знаннях тренери-викладачі мають виражену потребу. Відсутність взаємозв'язку між рівнем сформованості потребово-мотиваційно-ціннісної сфери професійної культури тренерів-викладачів і рівнем сфрормованості їх професійних знань дозволяє припустити, що спортивні педагоги практично не використовують свої знання в професійній діяльності, оскільки вони редуковані до професійних навичок і тим самим виведені зі сфрери свідомості.
\end{abstract}

Ключові слова: тренери-викладачі, професійні знання, потребово-мотиваційно-ціннісна сфера, професійна культура, професійні потреби.

\section{Vladimir Starchenko, Aleksandr Metelitsa}

\section{STUDY OF THE FORMATION LEVEL OF PROFESSIONAL KNOWLEDGE AND THE STATE OF THE NEED-MOTIVATION-VALUE SPHERE OF THE PROFESSIONAL CULTURE OF COACHES-TEACHERS}

\begin{abstract}
The article presents the results of the study of the formation level of professional knowledge and the state of the need-motivational-value sphere of the professional culture of coaches-teachers. Objective. Investigate the formation level of professional knowledge and the state of the need-motivational-value sphere of professional culture of coaches-teachers. The study covered coaches-teachers, whose total number was 81 persons (53 men and 28 women). Methods. Questionnaires, methods of mathematical statistics. Results. It has been established that the formation level of professional knowledge of trainers-teachers is "satisfactory", whereas that of their needmotivational-value sphere of professional culture is «good». It has been also established that there is no correlation between the formation level of professional knowledge and the state of the need-motivational-value sphere of professional culture of coaches. In terms of gender, there is no statistically significant difference between the levels of formation of professional knowledge of men's and women's coaches, as well as between those of their needmotivational-value sphere of professional culture. The findings indicate a low level of professional knowledge of coaches-teachers. Despite this, coaches-teachers have a pronounced need for professional knowledge. The lack of relationship between the formation level of need-motivational-value sphere of professional culture of coachesteachers and that of their professional knowledge suggests that sports teachers do not use their knowledge in professional activities, as they are reduced to professional skills and thus derived from sphere of consciousness. Keywords: coaches-teachers, professional knowledge, need-motivational-value sphere, professional culture, pro-
\end{abstract} fessional demands. 
Введение. Современный спорт переживает системный кризис, связанный с утратой ценностных ориентаций, с тенденцией превращения спортивных состязаний в постановочное цирковое шоу. К тому же на эффективность деятельности управленческих и тренерских кадров «шокирующее» действие оказывает окончание «эпохи допинга» ибо дальше решать вопросы подготовки спортивных кадров мирового уровня по десятилетиями отработанной схеме не получается. Вопрос «что делать дальше?» становится всё более острым. Ответ на этот вопрос должна дать спортивная наука, призванная вооружить тренерский корпус адекватной системой педагогических знаний, позволяющих повысить эффективность тренировочного процесса в новых условиях.

В этой связи большой научный и практический интерес представляет исследование уровня сформированности профессиональной культуры тренеров-преподавателей, который определяет их готовность к эффективной профессиональной деятельности.

При этом, как указывает Н. Л. Ильина, для тренера, чтобы успешно осуществлять свою деятельность, необходимо постоянно развивать и совершенствовать способности, связанные с различными компонентами своей профессиональной деятельности (проектировочный, организаторский, коммуникативный, гностический и двигательный) [2]. В свою очередь И. А. Пальшкова отмечает, что, несмотря на высокие требования к личности учителя как субъекта общей и профессиональной культуры современная система педагогического образования не готова обеспечить процесс её становления и развития [4]. В. Ф. Исаев выделяет четыре базовых уровня сформированности профессиональной культуры педагога: адаптивный, репродуктивный, эвристический и творческий [2].

В функциональном отношении профессиональная культура тренера может быть представлена как совокупность способов осуществления тренерской деятельности. В структурном отношении она являет собой систему, состоящую из взаимосвязанных элементов: профессионального мышления, потребностно-мотивационно-ценностной сферы (ПМЦС), профессиональных знаний, профессиональных умений и навыков, профессиональной подготовленности в тренерской деятельности, объединённых профессиональной деятельностью [5].

Среди элементов профессиональной культуры тренера особый интерес для нашего исследования представляет ПМЦС профессиональной культуры и профессиональные знания.

Это связано с тем, что ПМЦС профессиональной культуры является главной движущей силой, определяющей активность и заинтересованность тренера в осуществлении своей профессиональной деятельности, а профессиональные знания опред- еляют степень её осмысленности, целесообразности и эффективности. При этом, как отмечает Т. В. Хромина, недостаточный уровень сформированности профессиональных знаний у начинающих тренеров препятствует их приспособлению к профессиональной деятельности [12].

Актуальность нашего исследования определяется необходимостью диагностирования уровня сформированности ПМЦС профессиональной культуры тренера, уровня сформированности его профессиональных знаний, поиска взаимосвязей между ними.

Цель исследования - определить уровень сформированности профессиональных знаний и состояние потребностно-мотивационно-ценностной сферы профессиональной культуры тренеров-преподавателей.

Методы и организация исследования. При проведении исследования мы использовали метод анкетирования и методы математической статистики.

Исследование проводили на базе Института повышения квалификации и переподготовки кадров учреждения образования «Гомельский государственный университет имени Франциска Скорины» в период с октября 2018 по март 2019 г. В нём приняли участие тренеры-преподаватели по разным видам спорта в количестве 81 человека, проходившие курсы повышения квалификации. Среди них было 53 мужчины и 28 женщин. Средний возраст респондентов составил 42 года, а средний стаж работы - 18 лет.

Для диагностики уровня сформированности профессиональных знаний тренеров-преподавателей нами использовались специально разработанная анкета и методика обработки результатов анкетирования [9]. В соответствии со структурой и содержанием профессиональных знаний спортивного педагога все вопросы анкеты были разделены на четыре блока:

- первый блок (вопросы с 1-го по 5-й) направлен на диагностику уровня сформированности теоретических знаний;

- второй блок (вопросы с 6-го по 10-й) направлен на диагностику уровня сформированности практических знаний;

- третий блок (вопросы с 11-го по 15-й) направлен на диагностику уровня сформированности методических знаний, необходимых для обучения двигательным умениям и навыкам;

- четвёртый блок (вопросы с 16-го по 20-й) направлен на диагностику уровня сформированности методических знаний, необходимых для развития физических качеств.

Для определения состояния ПМЦС профессиональной культуры тренеров использовалась специальная диагностика, позволяющая определить уровень сформированности как всей ПМЦС их профессиональной культуры, так и её отдельных элементов [6]. В соответствии со структурой и со- 


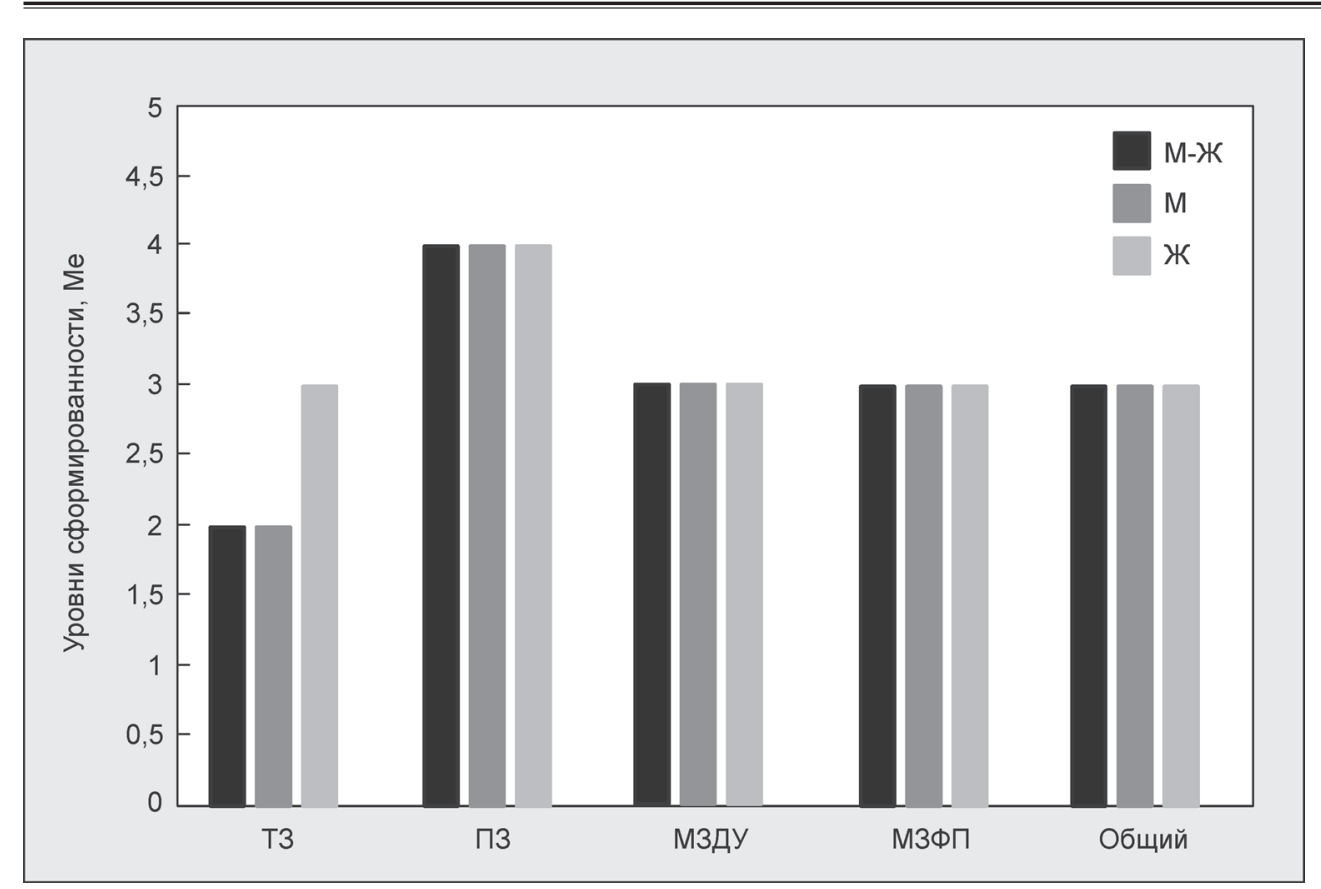

Рисунок 1 - Уровни сформированности профессиональных знаний тренеров: ТЗ - теоретические знания, ПЗ - практические знания, МЗДУ - методические знания, связанные с формированием двигательных умений и навыков, МЗФП методические знания, связанные с развитием физических качеств держанием ПМЦС профессиональной культуры спортивного педагога диагностическая анкета состоит из одного вопроса и 21 мотива. Мотивы 1-3 позволяют определить степень актуализации потребности в профессиональной деятельности, мотивы 4-6 - в профессиональных умениях и навыках, мотивы 7-9 - в профессиональной подготовленности, мотивы 10-12 - в профессиональных знаниях, мотивы 13-15 - в профессиональном мышлении, мотивы 16-21 - в профессиональной среде. Степень значимости для тренера каждого мотива оценивается по шкале от 0 до 5 , где 0 - отсутствие значимости, 5 - максимальная значимость. По степени актуализации всех профессиональных потребностей определяется уровень сформированности ПМЦС профессиональной культуры тренеров.

Поскольку уровень сформированности потребностей и значимости мотивов измеряли с помощью ранговой (порядковой) шкалы, то обработка результатов диагностики осуществляли с использованием такой статистической характеристики центральной тенденции выборки, как медиана (Ме). Соответственно проверка статистической гипотезы о принадлежности не связанных выборок к одной генеральной совокупности осуществлялась с помощью непараметрического критерия Манна-Уитни, а корреляционные отношения устанавливались путём вычисления рангового коэффициента корреляции Спирмена [7].

Результаты исследования и их обсуждение. Результаты исследования уровня сформированности профессиональных знаний тренеров-преподавателей представлены на рисунке 1.

Из рисунка 1 следует, что у тренеров-преподавателей медианный уровень сформированности профессиональных знаний удовлетворительный $(\mathrm{Me}=3)$. При этом, уровень сформированности теоретических знаний - неудовлетворительный $(\mathrm{Me}=2)$, практических знаний - хороший $(\mathrm{Me}=4)$, методических знаний (связанных с обучением двигательных умений и навыков) - удовлетворительный ( $\mathrm{Me}=3)$ и методических знаний, связанных с развитием физических качеств, удовлетворительный $(\mathrm{Me}=3)$.

Как по группе мужчин, так и по группе женщин медианный уровень сформированности профессиональных знаний оказался удовлетворительным $(\mathrm{Me}=3)$. При этом у мужчин уровень сформированности теоретических знаний - неудовлетворительный $(\mathrm{Me}=2)$, практических знаний - хороший $(\mathrm{Me}=4)$, методических знаний, связанных с обучением двигательных умений и навыков удовлетворительный $(\mathrm{Me}=3)$ и методических знаний, связанных с развитием физических качеств, также удовлетворительный ( $\mathrm{Me}=3)$.

$\mathrm{У}$ женщин уровень сформированности теоретических знаний удовлетворительный $(\mathrm{Me}=3)$, практических знаний - хороший $(\mathrm{Me}=4)$, методических знаний, связанных с обучением двигательных умений и навыков, - удовлетворительный $(\mathrm{Me}=3)$ и методических знаний, связанных с развитием физических качеств, также удовлетворительный $(\mathrm{Me}=3)$.

Проверка статистической гипотезы о достоверности отличий (с использованием непараметрического критерия Манна-Уитни) между уровнями сформированности профессиональных знаний у женщин и мужчин показала отсутствие статистически значимых отличий $(\mathrm{p}-$ level $=0,26)$.

По результатам анкетирования также были выявлены вопросы, на которые было получено 
наибольшее количество неправильных ответов. Соотношение правильных и неправильных ответов на вопросы анкеты представлено в таблице 1.

Представленные в таблице 1 результаты свидетельствуют, что на многие вопросы тренеры не смогли дать правильные ответы. При этом наибольшую сложность вызвали следующие вопросы:
- № 15 «Чем двигательное умение отличается от двигательного навыка?» (4 правильных и 77 неправильных ответов);

- № 20 «При воспитании выносливости, какой метод предусматривает последовательное варьирование нагрузки в ходе непрерывного упражнения?» (11 правильных и 70 неправильных ответов);

Таблица 1 - Соотношение правильных и неправильных ответов на вопросы анкеты

\begin{tabular}{|c|c|c|c|}
\hline \multirow{2}{*}{ № $\Pi / n$} & \multirow{2}{*}{ Вопросы } & \multicolumn{2}{|c|}{ Ответы } \\
\hline & & Правильные & Неправильные \\
\hline 1 & $\begin{array}{l}\text { Процесс, содержанием которого является обучение движениям, } \\
\text { воспитание физических качеств, овладение физкультурными знаниями и } \\
\text { формирование потребности в физкультурных занятиях называется... }\end{array}$ & 33 & 48 \\
\hline 2 & $\begin{array}{l}\text { Система, включающая физкультурное мышление, физкультурные } \\
\text { потребности и мотивы, физкультурные знания, двигательные умения } \\
\text { и навыки, физическую подготовленность, предназначенная для } \\
\text { осуществления человеком адекватной двигательной деятельности, } \\
\text { называется... }\end{array}$ & 26 & 55 \\
\hline 3 & $\begin{array}{l}\text { Процесс естественного становления и изменения на протяжении жизни } \\
\text { человека его антропометрических характеристик, физических качеств и } \\
\text { двигательных способностей называется... }\end{array}$ & 45 & 36 \\
\hline 4 & $\begin{array}{l}\text { Процесс воспитания физических качеств и овладения жизненно важными } \\
\text { движениями называется... }\end{array}$ & 29 & 52 \\
\hline 5 & $\begin{array}{l}\text { Исторически обусловленный идеал физического развития и физической } \\
\text { подготовленности человека, оптимально соответствующий требованиям } \\
\text { жизни, называется... }\end{array}$ & 41 & 40 \\
\hline 6 & Какое количество игроков играет в баскетболе в каждой команде? & 58 & 23 \\
\hline 7 & Расстояние между занимающимися в колонне называется... & 55 & 26 \\
\hline 8 & Основной формой физического воспитания школьников является... & 78 & 3 \\
\hline 9 & Какой размер имеет волейбольная площадка? & 53 & 28 \\
\hline 10 & $\begin{array}{l}\text { Строй, в котором занимающиеся расположены в затылок друг за другом, } \\
\text { называется... }\end{array}$ & 72 & 9 \\
\hline 11 & $\begin{array}{l}\text { Какая основная задача решается при начальном разучивании двигательно- } \\
\text { го действия? }\end{array}$ & 66 & 15 \\
\hline 12 & $\begin{array}{l}\text { Какой из методов преимущественно применяется при обучении } \\
\text { двигательных навыков? }\end{array}$ & 53 & 28 \\
\hline 13 & $\begin{array}{l}\text { Какое из перечисленных упражнений соответствует сопряжённому методу } \\
\text { воздействия при обучении двигательным навыкам? }\end{array}$ & 15 & 66 \\
\hline 14 & $\begin{array}{l}\text { Метод непосредственной наглядности при обучении кувырка вперёд по- } \\
\text { зволяет... }\end{array}$ & 63 & 18 \\
\hline 15 & Чем двигательное умение отличается от двигательного навыка? & 4 & 77 \\
\hline 16 & $\begin{array}{l}\text { Интервал отдыха, гарантирующий к моменту очередного повторения } \\
\text { упражнения восстановление работоспособности до исходного уровня, } \\
\text { называют... }\end{array}$ & 50 & 31 \\
\hline 17 & $\begin{array}{l}\text { Какие из перечисленных упражнений не используют в развитии собствен- } \\
\text { но силовых способностей? }\end{array}$ & 61 & 20 \\
\hline 18 & $\begin{array}{l}\text { Упражнения с сохранением неподвижного положения с предельной амп- } \\
\text { литудой в течение определённого промежутка времени относят к сред- } \\
\text { ствам... }\end{array}$ & 37 & 44 \\
\hline 19 & $\begin{array}{l}\text { Какой тест используют для определения уровня силы и силовой } \\
\text { выносливости? }\end{array}$ & 69 & 12 \\
\hline 20 & $\begin{array}{l}\text { При воспитании выносливости какой метод предусматривает последова- } \\
\text { тельное варьирование нагрузки в ходе непрерывного упражнения? }\end{array}$ & 11 & 70 \\
\hline
\end{tabular}




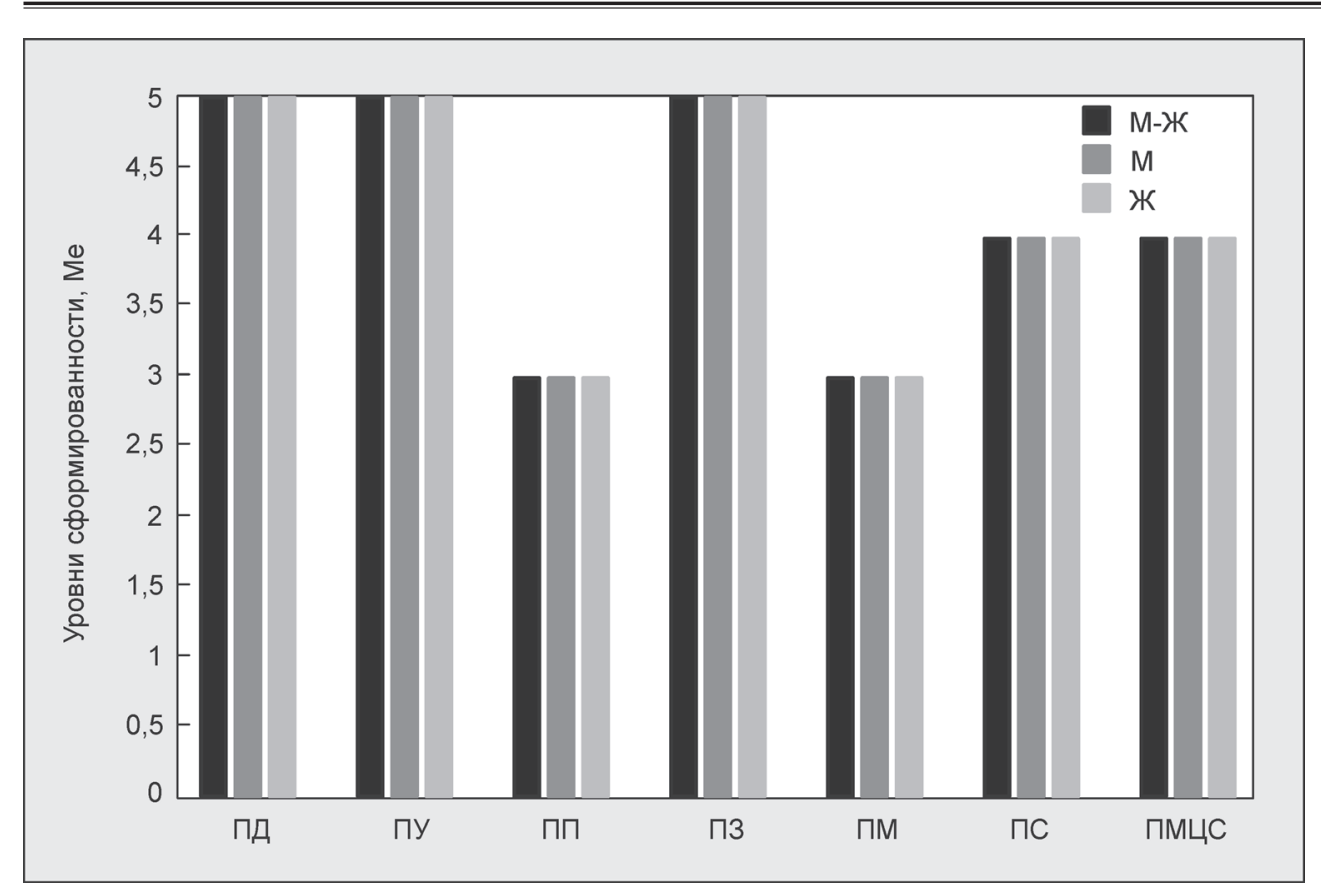

Рисунок 2-Уровни ссрормированности потребностномотивационно-ценностной сферы профессиональной культуры тренеров
- № 13 «Какое из перечисленных упражнений соответствует сопряжённому методу воздействия при обучении двигательных навыков?» (15 правильных и 66 неправильных ответов).

Результаты исследования уровня сформированности ПМЦС профессиональной культуры тренеров-преподавателей представлены на рисунке 2.

Из рисунка 2 следует, что медианный уровень сформированности ПМЦС профессиональной культуры тренеров-преподавателей по общей выборке $(\mathrm{n}=81)$ оказался хорошим $(\mathrm{Me}=4)$. При этом, медиана степени актуализации профессиональных потребностей составила:

- в профессиональной деятельности (ПД) - 5 баллов;

- в профессиональных умениях и навыках (ПУ) - 5 баллов;

- в профессиональной подготовленности (ПП) - 3 балла;

- в профессиональных знаниях (ПЗ) - 5 баллов;

- в профессиональном мышлении (ПМ) - 3 балла;

- в профессиональной среде (ПС) - 4 балла.

Статистически значимых отличий между уровнем сформированности ПМЦС профессиональной культуры женщин и мужчин обнаружено не было (p-level $=0,8)$.

Корреляционный анализ, проведённый с применением рангового коэффициента корреляции Спирмена, позволил исследовать зависимость между уровнем сформированности профессиональных знаний и уровнем сформированности ПМЦС профессиональной культуры тренеров (табл. 2).
Из таблицы 2 следует, что между:

- уровнем сформированности ПМЦС профессиональной культуры и уровнем сформированности профессиональных знаний статистически значимой связи нет;

- степенью актуализации потребностей в профессиональной деятельности, профессиональных умениях, профессиональной подготовленности, профессиональном мышлении, профессиональной среде и уровнем сформированности профессиональных знаний статистически значимая связь отсутствует;

- степенью актуализации потребности в профессиональных знаниях и уровнем сформированности профессиональных знаний существует очень слабая статистическая связь.

Отдельно по группе мужчин корреляционный анализ показал, что у них между:

- уровнем сформированности ПМЦС профессиональной культуры и уровнем сформированности профессиональных знаний статистически значимая связь отсутствует;

- степенью актуализации потребности в профессиональных знаниях и уровнем сформированности профессиональных знаний имеется очень слабая статистическая связь;

- степенью актуализации потребности в профессиональной подготовленности и уровнем сформированности профессиональных знаний существует очень слабая отрицательная статистическая связь;

- степенью актуализации потребностей в профессиональной деятельности, профессиональных умениях и навыках, профессиональном мышлении, профессиональной среде и уровнем сформирован- 
ности профессиональных знаний статистически значимая связь отсутствует.

По группе женщин корреляционный анализ показал наличие очень слабой статистической связи только между степенью актуализации потребности в профессиональных умениях и уровнем сформированности профессиональных знаний. По остальным параметрам статистической связи обнаружено не было.

Следует отметить, что научных работ, посвящённых исследованию уровня сформированности профессиональных знаний тренеров-преподавателей, весьма мало.

Результаты проведённого нами исследования свидетельствуют, что уровень сформированности профессиональных знаний тренеров-преподавателей не в полной мере отвечает современным требованиям к их профессиональной деятельности.

Сделанные нами выводы в целом согласуются с результатами исследований других авторов. Так, исследование, проведённое Я. О. Зайцевой, показало, что у тренеров по лёгкой атлетике уровень сформированности профессиональных знаний оценивается как почти хороший. При этом уровень сформированности теоретических знаний - неудовлетворительный, практических - очень хороший, методических знаний, связанных с обучением двигательных действий, - хороший, методических знаний, связанных с развитием физических качеств, - неудовлетворительный. Также в результате её исследования было выявлено, что между уровнем сформированности профессиональных знаний тренеров и результативностью их профессиональной деятельности статистическая взаимосвязь отсутствует [1].

Известно также исследование уровня сформированности профессиональных знаний 125 учителей физической культуры из разных областей Республики Беларусь, проведённое Е. В. Иванчи- ковой [8], в результате которого было установлено, что уровень сформированности профессиональных знаний учителей физкультуры удовлетворительный. При этом уровень сформированности теоретических профессиональных знаний неудовлетворительный, методических (связанных с обучением двигательных действий) - неудовлетворительный, методических (связанных с развитием физических качеств) - удовлетворительный, практических - отличный.

Таким образом, можно констатировать наличие проблемы, связанной с недостаточным уровнем сформированности профессиональных теоретических и методических знаний у физкультурноспортивных педагогов. В то же время, уровень сформированности ПМЦС профессиональной деятельности тренеров-преподавателей оказался хорошим. Полученные результаты согласуются с данными исследований других авторов. Так, по результатам своих исследований И. И. Таран установила, что тренеры-преподаватели ДЮСШ имеют высокий уровень мотивации профессиональной деятельности [10].

В исследовании А. О. Федосова было установлено, что у спортивных тренеров существует потребность в повышении своей квалификации в направлении поиска, обработки и использования современной профессиональной информации для повышения результативности подготовки спортсменов [11].

Таким образом, исходя из результатов приведённых исследований, можно утверждать, что, несмотря на недостаточность теоретической и методической подготовленности спортивных педагогов они в целом мотивированы относительно профессиональной деятельности.

Выводы. Полученные результаты свидетельствуют о невысоком уровне сформированности профессиональных знаний тренеров-преподавате-

Таблица 2 - Результаты анализа взаимосвязи между уровнем сформированности профессиональных знаний и уровнем сфрормированности ПМЦС профессиональной культуры тренеров

\begin{tabular}{|c|c|c|c|c|c|c|c|c|}
\hline \multirow{2}{*}{\multicolumn{2}{|c|}{ Параметры }} & \multicolumn{7}{|c|}{ Знания } \\
\hline & & \multirow{2}{*}{$\begin{array}{c}\text { ПмцுС } \\
0,045\end{array}$} & \multirow{2}{*}{$\begin{array}{c}\text { пд } \\
0,081\end{array}$} & \multirow{2}{*}{$\begin{array}{c}\text { пу } \\
0,08\end{array}$} & \multirow{2}{*}{$\begin{array}{c}\text { Пп } \\
-0,05\end{array}$} & \multirow{2}{*}{$\begin{array}{c}\text { П3 } \\
0,1\end{array}$} & \multirow{2}{*}{$\begin{array}{c}\text { Пм } \\
-0,006\end{array}$} & \multirow{2}{*}{$\begin{array}{c}\text { пс } \\
-0,023\end{array}$} \\
\hline $\begin{array}{l}\text { Ранговый коэффициент } \\
\text { корреляции Спирмена }\end{array}$ & $\begin{array}{l}\text { Мужчины и } \\
\text { женщины }\end{array}$ & & & & & & & \\
\hline Статистическая связь & & нет & нет & нет & нет & $\begin{array}{l}\text { очень } \\
\text { слабая }\end{array}$ & нет & нет \\
\hline $\begin{array}{l}\text { Ранговый коэффициент } \\
\text { корреляции Спирмена }\end{array}$ & Мужчины & 0,007 & 0,089 & 0,022 & $-0,102$ & 0,169 & $-0,014$ & $-0,070$ \\
\hline Статистическая связь & & нет & нет & нет & $\begin{array}{l}\text { очень слабая, } \\
\text { отрицательная }\end{array}$ & $\begin{array}{l}\text { очень } \\
\text { слабая }\end{array}$ & нет & нет \\
\hline $\begin{array}{l}\text { Ранговый коэффициент } \\
\text { корреляции Спирмена }\end{array}$ & Женщины & 0,087 & 0,023 & 0,151 & 0,066 & $-0,062$ & 0,052 & 0,040 \\
\hline Статистическая связь & & нет & нет & $\begin{array}{c}\text { очень } \\
\text { слабая }\end{array}$ & нет & нет & нет & нет \\
\hline
\end{tabular}


лей, что говорит об их неготовности к осмысленной, целенаправленной работе в новых условиях, требующих выхода на более высокий уровень понимания теоретических, методических и практических аспектов профессиональной деятельности. Вместе с тем, состояние ПМЦС профессиональной культуры тренеров-преподавателей в целом хорошее, что позволяет надеяться на преодоление профессиональных затруднений. Особую надежду вселяет то обстоятельство, что тренерыпреподаватели имеют выраженную потребность в профессиональных знаниях, то есть ощущают их недостаток. Однако отсутствие взаимосвязи между уровнем сформированности ПМЦС профессиональной культуры тренеров-преподавателей и уровнем сформированности их профессиональных знаний позволяет предположить, что спортивные педагоги практически не используют свои знания в профессиональной деятельности, поскольку они редуцированы до профессиональных навыков и тем самым выведены из сферы сознания. Однако новые условия осуществления профессиональной деятельности требуют выхода в рефлексивную позицию, использования профессионального мышления, продуцирования новых знаний, но тренерские кадры к этому не готовы. В этом заключается суть выявленной нами проблемы.

Перспективы дальнейших исследований предполагают исследование уровня сформированности профессиональных умений и навыков тренеровпреподавателей, а также взаимосвязи уровня сформированности элементов профессиональной культуры спортивных педагогов с результативностью их профессиональной деятельности.

Конфликт интересов. Авторы заявляют, что отсутствует какой-либо конфликт интересов.

\section{Литература}

1. Зайцева ЯО. Профессиональные знания и результативность педагогической деятельности тренеров по легкой атлетике. Актуальные проблемы формирования здорового образа жизни студенческой молодежи. Тез. Х Междунар. межвуз. науч.-практ. конф. студентов, 2018 Май 16; Смоленск. Смоленск: Нац. исслед. ун-т «МЭИ»; 2018, С. 98-101.

2. Ильина НЛ. Психология тренера: Учебное пособие. СПб: СПбГУ; 2016. 109 с.

3. Исаев ВФ. Профессионально-педагогическая культура преподавателя: учеб. пособие для студ. высш. учеб. заведений. Москва: Академия; 2002. 208 с.

4. Пальшкова ИА. Изучение проблемы профессионально педагогической культуры будущих учителей высшей школы. Вектор науки ТГУ. 2011; 2(5): 155-159.

5. Старчанка УМ. Структура і змест прафесійнай культуры спартыўнага педагога. Управление развитием образования в русле акмеологии. Материалы Междунар. науч.-практ. конф.; 2009; Гомель. Гомель: ГУО «ГОИРО»; 2009. Ч. 4, С. 44-47.

6. Старчанка УМ. Дыягностыка ПМКС прафесійнай культуры спартыўнага педагога. Актуальные вопросы научно-методической и учебно-организационной работы: инновационное управление вузом на основе системы менеджмента качества. Материалы науч.-метод. конф.; 2010 Март 11-12; Гомель. Гомель: ГГУ им. Ф. Скорины; 2010, С. 202-206.

7. Старчанка УМ. Спартыўная метралогія: вучэбны дапаможнік; М-ва адукацыі Рэспублікі Беларусь. Гомель: Гомел. дзярж. ун-т; 2017. 282 с.

8. Старченко ВН, Иванчикова ЕВ. Об уровне сформированности профессиональных знаний учителей фризической культуры и здоровья. Физическое воспитание, спорт, фризическая реабилитация и рекреация: проблемы и перспективы развития. Материалы V Междунар. электрон. науч.-практ. конф., 2016 Май 22-23; Красноярск. Красноярск: Сиб. гос. аэрокосмич; 2016, С. 125-130.

9. Старченко ВН, Метелица АН. Методика диагностики профессиональных знаний фризкультурно-спортивного педагога. Современное состояние и пути развития системы повышения квалификации и переподготовки специалистов в области физической культуры и спорта. Материалы Междунар. науч.-практ. конф.; 2014 Ноябрь 21; Минск. Минск: БГУФК; 2014, С. 111-114.

10. Таран ИИ, Ефимова СВ, Кяго АА. Исследование профессиональной направленности личности студентов физкультурного вуза и тренеров-преподавателей ДЮСШ. Гуманизация образования. 2017; 2: 32-37.

11. Федосов АО. Исследование сформированности информационно-аналитической компетенции тренеров по командным игровым видам спорта. Ученые записки. 2014; 6(112): 194-198.

12. Хромина ТВ, Якимова МИ, Лягина ЕЮ. Структура мотивации начинающих тренеров по плаванию в процессе адаптации к деятельности в условиях коммерческого спортивного клуба. Известия Тульского государственного университета. Физическая культура. Спорт. 2017; 2: 192-198.

\section{Literature}

1. Zaytseva YO. Professional knowledge and the effectiveness of the educational activities of athletics trainers. Actual problems of forming a healthy lifestyle for students. Tez. X Mezhdunarodnoy nauchno-prakticheskoy konferentsiyi studentov, 2018 May 16; Smolensk: Natsionalny issledov. universitet «MEl»; 2018, P. 98-101.

2. Ilyina NL Coach psychology: Teaching guide. Saint Petersburg: SPGU; 2016. 109 p. 
3. Isayev VF. Professional-pedagogical culture of a teacher: teaching guide for students. Moscow: Akademiya; 2002. 208 p.

4. Palyshkova IA. Studying the problem of professionally pedagogical culture of future teachers of higher education. Vektor nauki TGU. 2011; 2(5): 155-159.

5. Starchanka UM. Структура і змест прафесійнай культуры спартыўнага педагога. Management of education development in line with acmeology. Materialy mezhdunarodnoy nauchno-prakticheskoy konferentsiyi; 2009; Gomel. Gomel: GUO «GOIRO»; 2009. P. 4, P. 44-47.

6. Starchanka UM. Дыягностыка ПМКС прафесійнай культуры спартыўнага педагога. Actual issues of scientific-methodological and educational-organizational work: innovative university management based on a quality management system. Materialy nauchno-metodicheskoy konferentsiyi; 2010 March 11-12; Gomel. Gomel: GGU im. F. Skorina; 2010, P. 202-206.

7. Starchanka UM. Спартыўная метралогія: вучэбны дапаможнік; М-ва адукацыі Рэспублікі Беларусь. Гомель: Гомел. дзярж. ун-т; 2017. 282 р.

8. Starchenko VN, Ivanchikova EV. On the level of professional knowledge of teachers of physical education and health. Physical education, sports, physical rehabilitation and recreation:problems and development prospects. Materialy V mezhdunarodnoy nauchno-prakticheskoy konferentsiyi, 2016 May 22-23; Krasnoyarsk. Krasnoyarsk: Sib. gos. aerokosmich; 2016, P. 125-130.

9. Starchenko VN, Metelitsa AN. Methods for diagnosing professional knowledge of a sports teacher. The current state and ways of developing a system of advanced training and retraining of specialists in the field of physical education and sport. Materialy mezhdunarodnoy nauchno-prakticheskoy konferentsiyi; 2014 November 21; Minsk. Minsk: BGUFK; 2014, P. 111-114.

10. Taran II, Efimova SV, Kyago AA. The study of the professional orientation of the personality of students of a sports university and coaches-teachers of sports schools. Humanization of Education. 2017; 2: 32-37.

11. Fedosov AO. The study of the formation of information and analytical competence of coaches in team game sports. Uchenyye zapiski. 2014; 6(112): 194-198.

12. Khromina TV, Yakimova MI, Lyagina EY. Motivation structure of novice swimming trainers in the process of adapting to activities in a commercial sports club. Izvestiya Tulskogo gosudarstvennogo universiteta. Fizicheskaya kultura. Sport. 2017; 2: 192-198.

\section{Інформація про авторів}

Метелица Александр Николаевич

https://orcid.org/

metelitsa1985@mail.ru

Старченко Владимир Николаевич

https://orcid.org/

Starch@narod.ru

Гомельский государственный

университет имени Франциска Скорины

246000, Советская 108, ауд. 1-24 г. Гомель,

Республика Беларусь

\section{Information about the authors}

Miatselitsa Aliaksandr

https://orcid.org/

metelitsa1985@mail.ru

Starchanka Uladzimir

https://orcid.org/

Starch@narod.ru

Francisk Skorina Gomel State University

Sovetskaya 108, Gomel, Republic of Belarus 